\title{
Prevalence of physical activity and associated factors among pregnant women: a cross-sectional population-based study in southern Brazil
}

Vilson Rodrigues da Silva 1

iD https://orcid.org/0000-0003-2891-267X

Antonio Fernando Boing 2

iD https://orcid.org/0000-0003-2612-7272

Departament of Public Health. Federal University of Santa Catarina. Rua Delfino Conti, s.n. Trindade. Florianopolis, SC, Brazil. CEP: 88.040-900. E-mail: rodriguesdasilvavilson@gmail.com

2 Postgraduate Program in Collective Health. Health Sciences Center. Federal University of Santa Catarina. Florianopolis, SC, Brazil.

\begin{abstract}
Objectives: to describe the prevalence of sufficient leisure-time physical activity (LPA) in the trimesters of pregnancy and to test its association with sociodemographic and contextual characteristics.

Methods: cross-sectional study that in 2019 analyzed data from 3580 pregnant women residing in Santa Catarina, Brazil. LPA was categorized as "active" (150 minutes or more of LPA/week) and "inactive" (less than 150 minutes).

Results: the prevalence for the recommended level of LPA was $15.3 \%(C 195 \%=14.1$ 16.4) before pregnancy, gradually declining to $7.8 \%(C 195 \%=7.3-8.7), 7.3 \%(C 195 \%=6.5$ $8.2)$, and $5.8 \%(C 195 \%=5.1-6.7)$ in the following trimesters of pregnancy. Higher level of education was associated with the four outcomes, increasing the chance of being active by $79 \%$ in the third trimester of pregnancy. In the second trimester, living in a neighborhood that stimulates physical activity increased the chance of being active by $39 \%$. In the third trimester, having received guidance from a health professional was associated with an increase of $60 \%$ in the chance of practicing $L P A$.

Conclusion: the prevalence of recommended LPA is low among pregnant women and living in a neighborhood favorable to outdoor practices, greater education level and receiving guidance from health professionals increased the chance of pregnant women to be active.
\end{abstract}

Key words Leisure activities, Pregnancy, Neighborhood, Prenatal, Epidemiology 


\section{Introduction}

The leisure-time physical activity (LPA) is positively associated with positive outcomes for the health of women and children to be born. ${ }^{1}$ It is associated with a lower risk for development of gestational diabetes, hypertension, excessive gestational weight gain, preeclampsia and symptoms of postpartum depression. 1,2 In addition, so far it is highlighted that there is no evidence of negative effects of moderate physical activity in healthy pregnant women. 3

The prevalence of LPA among pregnant women varies substantially according to the literature, ranging from $4.4 \%$ to $47.1 \%$ between different countries and methods used.2,4 In Brazilian pregnant women, national studies have shown a low prevalence of this outcome. A research conducted in Pelotas, Rio Grande do Sul, found that only $4.7 \%$ of women were active during pregnancy 2 and another study conducted in Campina Grande, Paraíba, found that $98.3 \%$ of pregnant women were sedentary in the 24th week of pregnancy. 5 However, there are few studies conducted with Brazilian pregnant women from a large and probabilistic sample.

Individual factors have been identified in epidemiological studies as being associated with the practice of LPA among pregnant women. Among them, sociodemographic characteristics stand out for their consistency and magnitude, with a higher prevalence of physical activity being observed among women with a higher educational level, family income, who live with their partner and are white. 2,4 However, given the complexity of factors that influence human behaviors related to healthy lifestyle habits during pregnancy, only individual characteristics do not explain all the interpersonal variability observed in the practice of LPA in studies. ${ }^{6}$ As many individual behaviors are influenced by the living environment, epidemiological studies have started to explore this dimension in the causal models of health outcomes. ${ }^{7}$ However, these studies are still incipient among pregnant women

It is known that the environment around the house has an important influence on people's lifestyles and their choices for healthy habits.? According to $\mathrm{WHO},{ }^{8}$ several environmental factors can discourage people from becoming more active, such as fear of violence, crime in outdoor areas, high-density traffic, pollution and lack of parks, sidewalks and sports facilities.

It is also noteworthy that few studies were found in the worldwide literature on PA among pregnant women that included aspects of the living environment among their exploratory variables.7,9,10 In addition, these studies were carried out in middleand upper-income countries, an aspect that indicates the need to study the topic in low- and middleincome countries, particularly in those with high socioeconomic inequalities and high occupation of urban space, such as Brazil. Thus, the aim of this study was to describe the prevalence of physical activity in pregnant women and to test its association with individual contextual and sociodemographic factors.

\section{Methods}

A population-based cross-sectional study was carried out with pregnant women who performed their prenatal care exclusively in consultations by the Unified Health System - Sistema Único de Saúde (SUS) or who did not perform prenatal care. The study was conducted in the State of Santa Catarina, which in 2019 had an estimated population of 7189261 people, $50.4 \%$ were women. In 2018 , the fertility rate in the state was 1.74 children per woman of childbearing age, the infant mortality rate was 9.93 deaths per 1000 born alive and the maternal death rate equal to 38.64 per 100000 born alive. 11,12 In 2014, the health care network in Santa Catarina had 204 general hospitals, 36 of which were public ones, 82 philanthropic and 85 private ones. 13

The reference population consisted of pregnant women of any age living in Santa Catarina, who had children with at least 22 weeks pregnancy and $500 \mathrm{~g}$ of weight in state hospitals from January to August 2019. All hospitals and maternities that assisted people by SUS with 500 or more births in 2016 participated in the study. Women whose births occurred in extra-hospital settings, who underwent consultations for their prenatal care at least partially in the private health service network and/or who were not in a physical or emotional condition to answer the questions were excluded from the study. Pregnant women who chose not to participate in the study or who wished not being part of it at any time were considered refusals.

The sample size was calculated for a prevalence study, predicting a $50 \%$ prevalence, margin of error of 1.6 , population size of 50 thousand, $95 \%$ confidence level and $5 \%$ for replacement of losses, totaling 3665 women. The number of interviews for each hospital/maternity was defined in proportion to the number of deliveries carried out in 2016. A pilot study was carried out with $5 \%$ of the total sample calculated to assess field dynamics. The sample statistical power was calculated a posteriori. The sample obtained in this study enabled to identify a 
minimum relative risk of 1.38 , considering alpha error of $5 \%$, power of $80 \%$, non-exposed: exposed ratio of $1: 1$ and prevalence in the non-exposed of $8.0 \%$.

Pregnant women were interviewed in the hospital or maternity face-to-face until 48 hours after delivery. The interviewers selected and trained to conduct data collections had at least completed high school, 18 years old and dedication to the project to guarantee coverage of all deliveries that occurred in the period.

Accessibility was guaranteed, through translators or companions, for pregnant women who did not speak Portuguese or who had any disability that would constitute a barrier to their communication. Data were collected using tablets and periodically transmitted from each municipality to the central database of the research. The technical team performed quality control of the data periodically by randomly selecting $10 \%$ of the sample.

The analyzed outcomes were the appropriate level of LPA in four semesters (pre-gestational semester; first, second and third gestational semesters). Women were categorized as "Active" (at least 150 minutes of leisure-time physical activity per week) and "Not active" (leisure-time physical activity for less than 150 minutes a week or did not practice any LPA), according to the recommendations of the American College of Obstetricians and Gynecologists (ACOG). ${ }^{14}$

These outcomes were obtained from the questions about the practice of PA in the analyzed periods (yes or no) and about the weekly frequency and time dedicated each time. These variables were collected as follows: 1) "Not considering the activity at home or at work, did you do any type of regular physical exercise (at least 2 times a week) during pregnancy?", With alternatives "Yes", "No" and "Do not know or do not want to inform"; 2) "On average, how many times a week? ", For the alternatives of "1 day", "2 days", "3 days", "4 days", "5 days", "6 days", "7 days" and "Do not know or do not want to inform"; 3) "On average, how long each time?", answered in minutes. The question format was the same for the pre-pregnancy period.

As individual exploratory variables, were analyzed age (13-19 years old, 20-34 years old or $35-46$ years old), education ( $\leq 9$ years of study, 10 12 years or $\geq 13$ years), per capita household income (categorized in quartiles), skin color/self-reported race (white, brown or black), living with husband or partner (yes or no), receiving guidance from a health professional during prenatal care to practice PA (yes or no) and be working (yes or no).
The contextual exploratory variables that assessed the pregnant women's neighborhood environment were social cohesion (yes or no), episodes of violence (yes or no) and encouragement to physical activity (yes or no). The social cohesion variable in the neighborhood was positive when the interviewee answered positively to two questions: "In your neighborhood, are people willing to help the neighbors?" and "Is your neighborhood very close, that is, are people able to unite around common interests?" The variable living in an area with violence was positive when the pregnant woman answered no to the question "Do you feel safe walking day or night in your neighborhood?" and often or sometimes when asked "In the past 6 months, how often has robbery been occurring?" The living environment was considered to stimulate physical activity when the mothers answered yes to the following questions: "Does your neighborhood offer many conditions for people to be physically active (for example, can they go jogging, cycling, etc.)?" and "Is it pleasant to go jogging in your neighborhood?".

First, the relative and absolute frequencies for the outcomes of pre-pregnancy physical activity and during pregnancy for each of the explanatory variables were analyzed. After that, univariate logistic regression was performed to obtain the magnitude of possible associations among each selected explanatory variable with the analyzed outcomes. Finally, multivariate logistic regression was performed to obtain the adjusted magnitudes of the relationships between the outcomes and each of the independent variables, estimated using the Odds Ratio (OR) as a measure of association, along with the respective $95 \%$ confidence intervals. Variables whose Wald test reported a $p$-value less than 0.05 were considered associated with the outcome in the final model. All variables were included in the multiple models and the data were analyzed using the Stata 14.0 program.

The research was approved by the Research Ethics Committee with human beings of the Federal University of Santa Catarina, according to CAAE 53671016110010121. With all participants, the awareness of and agreement with the objectives and ethical aspects of the research were obtained, through explanation and signing of the Informed Consent Form, to ensure compliance with the standards described in resolution CNS 510/2016.

\section{Results}

A total of 3580 pregnant women participated in the study, equivalent to a response rate of $97.7 \%$. Most 
of the sample consisted of women who declared themselves as white (63.4\%), aged between 20 and 34 years old $(71.3 \%)$ and with at least complete high school education (65.5\%). It was also observed that four out of five pregnant women lived with their husband or partner, $54 \%$ of them worked and $60 \%$ reported having received professional guidance to practice physical activity. As for the neighborhood environment, $82.9 \%$ of the interviewees lived in a neighborhood with social cohesion, $84.0 \%$ in a neighborhood with violence and $66.0 \%$ in a neighborhood that encourages physical activity (Table 1).

The general prevalence for the recommended level of LPA (at least 150 minutes per week) was $15.3 \%(\mathrm{CI} 95 \%=14.1-16.4)$ before pregnancy, gradually declining to $7.8 \%(\mathrm{CI} 95 \%=7.3-8.7)$ in the first trimester, $7.3 \%(\mathrm{CI} 95 \%=6.5-8.2)$ in the second one and $5.8 \%(\mathrm{CI} 95 \%=5.1-6.7)$ in the third trimester of

Table 1

Sample distribution and prevalence of physical activity (PA) in the pre-pregnancy period and during pregnancy. Santa Catarina, Brazil, 2019.

\begin{tabular}{|c|c|c|c|c|c|c|}
\hline & \multicolumn{2}{|c|}{ Sample } & \multicolumn{3}{|c|}{ Prevalence \% (Cl95\%) } & \multirow[b]{2}{*}{$3^{\circ}$ Trimester } \\
\hline & $n$ & $\%$ & Pre-pregnancy & $1^{\circ}$ Trimester & $2^{\circ}$ Trimester & \\
\hline The entire sample & 3,580 & 100.0 & $15.3(14.1-16.4)$ & $7.8(7.3-8.7)$ & $7.3(6.5-8.2)$ & $5.8(5.1-6.7)$ \\
\hline \multicolumn{7}{|l|}{ Age range (years old) } \\
\hline $13-19$ & 511 & 14.3 & $13.3(10.6-16.6)$ & $6.7(5.0-9.4)$ & $6.9(4.0-9.5)$ & $6.1(4.3-8.6)$ \\
\hline $20-34$ & 2,548 & 71.3 & $15.2(13.8-16.7)$ & $7.9(6.9-9.0)$ & $7.3(6.4-8.5)$ & $5.9(5.1-6.9)$ \\
\hline $35-46$ & 513 & 14.4 & $17.4(14.3-20.9)$ & $8.4(6.3-11.1)$ & $7.2(5.3-9.8)$ & $5.0(3.5-7.4)$ \\
\hline \multicolumn{7}{|l|}{ Color/race } \\
\hline White & 2,205 & 63.4 & $14.5(13.1-16.1)$ & $7.8(6.8-9.0)$ & $7.2(6.2-8.3)$ & $5.5(4.6-6.6)$ \\
\hline Brown & 941 & 27.1 & $17.0(14.8-19.6)$ & $7.8(6.3-9.8)$ & $7.7(6.1-9.6)$ & $6.8(5.4-8.6)$ \\
\hline Black & 330 & 9.5 & $11.4(8.4-15.4)$ & $7.0(4.7-10.4$ & $6.4(4.2-9.6)$ & $4.3(2.6-7.1)$ \\
\hline \multicolumn{7}{|c|}{ Living with husband/companion } \\
\hline No & 695 & 19.5 & $13.4(11.1-16.2)$ & $6.6(5.0-8.8)$ & $6.5(4.9-8.6)$ & $4.4(3.1-6.2)$ \\
\hline Yes & 2,864 & 80.5 & $15.8(14.5-17.1)$ & $8.1(7.2-9.2)$ & $7.5(6.6-8.5)$ & $6.2(4.5-7.1)$ \\
\hline \multicolumn{7}{|l|}{ Education (years of study) } \\
\hline$\leq 9$ & 1,218 & 34.5 & $9.7(8.2-11.5)$ & $5.7(4.5-7.1)$ & $5.6(4.4-8.6)$ & $4.6(3.6-6.0)$ \\
\hline $10-12$ & 1,853 & 52.5 & $16.3(14.7-18.1)$ & $8.8(7.6-10.2)$ & $8.2(7.0-9.5)$ & $6.5(5.5-7.7)$ \\
\hline$\geq 13$ & 458 & 13.0 & $24.7(20.9-28.9)$ & $9.2(6.9-12.2)$ & $8.5(6.3-11.5)$ & $6.8(4.8-9.5)$ \\
\hline \multicolumn{7}{|l|}{ Household income per capita } \\
\hline Quartile 1 (the poorest) & 910 & 26.8 & $13.0(10.9-15.3)$ & $7.9(6.3-9.9)$ & $7.7(6.1-9.6)$ & $5.7(4.4-7.5)$ \\
\hline Quartile 2 & 789 & 23.2 & $13.6(11.4-16.2)$ & $6.4(4.9-8.3)$ & $6.4(4.9-8.3)$ & $5.6(4.2-7.4)$ \\
\hline Quartile 3 & 852 & 25.1 & $15.6(13.3-18.2)$ & $9.0(7.2-11.1)$ & $7.8(6.2-9.8)$ & $6.7(5.2-8.7)$ \\
\hline Quartile 4 (the richest) & 844 & 24.9 & $14.5(16.0-21.3)$ & $8.2(6.5-10.3)$ & $7.9(6.2-9.9)$ & $5.8(4.4-7.6)$ \\
\hline \multicolumn{7}{|l|}{ Working } \\
\hline No & 1,630 & 46.0 & $17.1(15.4-19.1)$ & $7.5(6.3-8.9)$ & $6.7(5.6-8.0)$ & $5.1(4.2-6.4)$ \\
\hline Yes & 1,914 & 54.0 & $13.6(12.2-15.3)$ & $8.1(7.9-9.5)$ & $7.9(6.8-9.2)$ & $6.4(5.4-7.6)$ \\
\hline \multicolumn{7}{|l|}{ Received guidance from a } \\
\hline \multicolumn{7}{|l|}{ health professional } \\
\hline No & 1,401 & 39.9 & - & $5.6(4.5-6.9)$ & $5.1(4.1-6.4)$ & $4.4(3.4-5.6)$ \\
\hline Yes & 2,109 & 60.1 & - & $9.4(8.2-10.8)$ & $8.9(7.8-10.2)$ & $7.0(6.0-8.2)$ \\
\hline \multirow{2}{*}{\multicolumn{7}{|c|}{$\begin{array}{l}\text { Lives in a neighborhood with } \\
\text { social cohesion }\end{array}$}} \\
\hline & & & & & & \\
\hline Yes & 2,809 & 82.9 & $13.8(12.0-15.9)$ & $7.1(5.3-9.5)$ & $6.2(4.5-8.5)$ & $5.5(3.9-7.7)$ \\
\hline No & 581 & 17.1 & $15.5(14.2-16.9)$ & $8.2(7.2-9.2)$ & $7.8(6.9-8.9)$ & $5.9(5.1-6.9)$ \\
\hline \multirow{2}{*}{\multicolumn{7}{|c|}{$\begin{array}{l}\text { Lives in a neighborhood } \\
\text { with violence }\end{array}$}} \\
\hline & & & & & & \\
\hline No & 2,897 & 84.0 & $13.2(10.6-16.3)$ & $7.9(6.9-8.9)$ & $7.2(6.3-8.2)$ & $5.9(5.1-6.8)$ \\
\hline Yes & 553 & 16.0 & $15.5(14.2-16.9)$ & $7.1(5.3-9.5)$ & $7.1(5.2-9.6)$ & $5.6(4.0-7.9)$ \\
\hline \multirow{2}{*}{\multicolumn{7}{|c|}{$\begin{array}{l}\text { Lives in a neighborhood that } \\
\text { encourages physical activity }\end{array}$}} \\
\hline & & & & & & \\
\hline No & 1,189 & 34.0 & $13.8(12.0-15.9)$ & $6.7(5.3-8.2)$ & $6.0(4.8-7.5)$ & $5.1(4.0-6.6)$ \\
\hline Yes & 2,305 & 66.0 & $16.1(14.7-17.7)$ & $8.7(7.6,10.0)$ & $8.2(7.2-9.4)$ & $6.4(5.4-7.4)$ \\
\hline
\end{tabular}


pregnancy. The stratum with the highest prevalence of LPA in the pre-pregnancy period was women with a high level of education (24.7\%). During pregnancy, the highest values were observed among those who received a medical recommendation for physical activity (ranging from $9.4 \%$ to $7.0 \%$ ), followed by those with high education (Table 1).

Table 2 shows the results of the crude analysis. It was identified that having more years of study, receiving guidance from a health professional and living in a neighborhood that encourages the practice of physical activities (except for the third trimester) were aspects that increased the chances of being active during pregnancy. For the pre-pregnancy period, having higher education, higher income and living in a neighborhood that encourages the practice of PA had a positive association with the outcome, and working was negatively associated with it.

In the adjusted model (Table 3 ), only education had a significant association with all four outcomes analyzed. For outcomes in the three months prior to pregnancy and in the first, second and third trimesters of pregnancy, respectively, there was a $201 \%, 56 \%, 65 \%$ and $79 \%$ greater chance of, remain active the pregnant women with higher education compared to those with less years of study. In the second trimester of pregnancy, living in a neighborhood that stimulates PA increased the chance of being active by $39 \%$. And in the third semester, having received guidance from a health professional was associated with a $60 \%$ increase in the chance of practicing enough LPA.

Regarding only the pre-pregnancy period, it was

\section{Table 2}

Crude model of factors associated with the practice of physical activity (PA) in the pre-pregnancy period and during pregnancy. Santa Catarina, Brazil, 2019.

\begin{tabular}{|c|c|c|c|c|c|c|c|c|}
\hline & 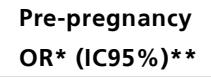 & $p$ & $\begin{array}{c}1^{\circ} \text { Trimester } \\
\text { OR* }(\mathrm{Cl} 95 \%)^{* *}\end{array}$ & $p$ & $\begin{array}{c}2^{\circ} \text { Trimester } \\
\text { OR* }(\mathrm{Cl} 95 \%) * *\end{array}$ & $p$ & $\begin{array}{c}3^{\circ} \text { Trimester } \\
\text { OR* }(\mathrm{C} 195 \%)^{* *}\end{array}$ & $p$ \\
\hline Age range (years old) & & 0.072 & & 0.366 & & 0.837 & & 0.484 \\
\hline $13-19$ & 1 & & 1 & & 1 & & 1 & \\
\hline $20-34$ & $1.17(0.88-1.54)$ & & $1.66(0.80-1.69)$ & & $1.08(0.74-1.57)$ & & $0.97(0.65-1.44)$ & \\
\hline $35-46$ & $1.37(0.97-1.93)$ & & $1.24(0.78-1.97)$ & & $1.05(0.65-1.70)$ & & $0.82(0.48-1.40)$ & \\
\hline Color/race & & 0.125 & & 0.990 & & 0.686 & & 0.215 \\
\hline White & 1 & & 1 & & 1 & & 1 & \\
\hline Brown & $1.21(0.98-1.49)$ & & $1.01(0.76-1.34)$ & & $1.07(0.80-1.44)$ & & $1.25(0.91-1.71)$ & \\
\hline Black & $0.76(0.53-1.09)$ & & $0.89(0.57-1.40)$ & & $0.89(0.55-1.42)$ & & $0.77(0.44-1.35)$ & \\
\hline Lives with husband/companion & & 0.125 & & 0.202 & & 0.371 & & 0.066 \\
\hline No & 1 & & 1 & & 1 & & 1 & \\
\hline Yes & $1.21(0.95-1.54)$ & & $1.25(0.89-1.72)$ & & $1.66(0.83-1.62)$ & & $1.45(0.98-2.16)$ & \\
\hline Education (years of study) & & $<0.001$ & & 0.002 & & 0.009 & & 0.034 \\
\hline$\leq 9$ & 1 & & 1 & & 1 & & 1 & \\
\hline $10-12$ & $1.81(1.44-2.28)$ & & $1.61(1.20-2.15)$ & & $1.50(1.12-2.02)$ & & $1.43(1.04-1.99)$ & \\
\hline$\geq 13$ & $3.04(2.29-4.05)$ & & $1.68(1.13-2.50)$ & & $1.57(1.04-2.36)$ & & $1.50(0.95-2.36)$ & \\
\hline Household income per capita & & 0.001 & & 0.426 & & 0.6691 & & 0.705 \\
\hline Quartile 1 (the poorest) & 1 & & 1 & & 1 & & 1 & \\
\hline Quartile 2 & $1.06(0.80-1.40)$ & & $0.79(0.54-1.15)$ & & $0.81(0.56-1.19)$ & & $0.97(0.64-1.47)$ & \\
\hline Quartile 3 & $1.24(0.95-1.62)$ & & $1.15(0.82-1.61)$ & & $1.02(0.72-1.44)$ & & $1.19(0.80-1.75)$ & \\
\hline Quartile 4 (the richest) & $1.52(1.17-1.98)$ & & $1.04(0.74-1.47$ & & $1.02(0.72-1.45)$ & & $1.01(0.68-1.52)$ & \\
\hline Working & & 0.004 & & 0.495 & & 0.186 & & 0.135 \\
\hline No & 1 & & 1 & & 1 & & 1 & \\
\hline Yes & $0.76(0.64-0.92)$ & & $1.09(0.85-1.40)$ & & $1.19(0.92-1.54)$ & & $1.24(0.93-1.65)$ & \\
\hline \multicolumn{9}{|l|}{ Received guidance from a } \\
\hline health professional & & - & & $<0.001$ & & $<0.001$ & & 0.001 \\
\hline No & - & & 1 & & 1 & & 1 & \\
\hline Yes & - & & $1.76(1.34-2.31)$ & & $1.82(1.37-2.42)$ & & $1.65(1.21-2.24)$ & \\
\hline \multicolumn{9}{|l|}{ Lives in a neighborhood with } \\
\hline social cohesion & & 0.283 & & 0.393 & & 0.188 & & 0.708 \\
\hline Yes & 1 & & 1 & & 1 & & 1 & \\
\hline No & $0.87(0.67-1.12)$ & & $0.86(0.61-1.21)$ & & $0.78(0.54-1.13)$ & & $0.93(0.63-1.37)$ & \\
\hline
\end{tabular}


Crude model of factors associated with the practice of physical activity (PA) in the pre-pregnancy period and during pregnancy. Santa Catarina, Brazil, 2019.

\begin{tabular}{|c|c|c|c|c|c|c|c|c|}
\hline & $\begin{array}{l}\text { Pre-pregnancy } \\
\text { OR* (IC95\%)** }\end{array}$ & $p$ & $\begin{array}{c}1^{\circ} \text { Trimester } \\
\text { OR* }(\mathrm{Cl} 95 \%)^{* *}\end{array}$ & $p$ & $\begin{array}{c}2^{\circ} \text { Trimester } \\
\mathrm{OR}^{*}(\mathrm{Cl} 95 \%)^{* *}\end{array}$ & $p$ & $\begin{array}{c}3^{\circ} \text { Trimester } \\
\text { OR* }(\mathrm{Cl} 95 \%)^{* *}\end{array}$ & $p$ \\
\hline \multicolumn{9}{|l|}{ Lives in a neighborhood } \\
\hline with violence & & 0.166 & & 0.522 & & 0.913 & & 0.804 \\
\hline No & 1 & & 1 & & 1 & & 1 & \\
\hline Yes & $0.83(0.63-1.08)$ & & $0.89(0.63-1.27)$ & & $0.98(0.69-1.0)$ & & $0.95(0.64-1.41)$ & \\
\hline \multicolumn{9}{|l|}{ Lives in a neighborhood that } \\
\hline encourages physical activity & & 0.076 & & 0.033 & & 0.018 & & 0.160 \\
\hline No & 1 & & 1 & & 1 & & 1 & \\
\hline Yes & $1.20(0.98-1.46)$ & & $1.34(1.02-1.76)$ & & $1.41(1.06-1.86)$ & & $1.24(0.92-1.70)$ & \\
\hline
\end{tabular}

*Odds Ratio; **95\%Confidence Interval.

Table 3

Adjusted model of factors associated with physical activity (PA) in the pre-gestational period and during pregnancy. Santa Catarina, Brazil, 2019.

\begin{tabular}{|c|c|c|c|c|c|c|c|c|}
\hline & $\begin{array}{l}\text { Pre-pregnancy } \\
\text { OR* }(\text { IC95\%)** }\end{array}$ & $p$ & $\begin{array}{c}1^{\circ} \text { Trimester } \\
\text { OR* }(\mathrm{Cl} 95 \%)^{* *}\end{array}$ & $p$ & $\begin{array}{c}2^{\circ} \text { Trimester } \\
\text { OR* }(\mathrm{Cl} 95 \%)^{* *}\end{array}$ & $p$ & $\begin{array}{c}3^{\circ} \text { Trimester } \\
\text { OR* }(\mathrm{Cl} 95 \%) * *\end{array}$ & $p$ \\
\hline Age range (years old) & & 0.060 & & 0.151 & & 0.609 & & 0.957 \\
\hline $13-19$ & 1 & & 1 & & 1 & & 1 & \\
\hline $20-34$ & $1.17(0.83-1.65)$ & & $1.20(0.77-1.88)$ & & $1.12(0.73-1.74)$ & & $1.15(0.71-1.87)$ & \\
\hline $35-46$ & $1.51(1.00-2.29)$ & & $1.56(0.91-2.67)$ & & $1.23(0.71-2.12)$ & & $1.10(0.59-2.05)$ & \\
\hline Color/race & & 0.029 & & 0.337 & & 0.222 & & 0.076 \\
\hline White & 1 & & 1 & & 1 & & 1 & \\
\hline Brown & $1.32(1.04-1.66)$ & & $1.13(0.83-1.54)$ & & $1.19(0.87-1.62)$ & & $1.36(0.97-1.90)$ & \\
\hline Black & $0.81(0.54-1.21)$ & & $1.06(0.66-1.71)$ & & $1.02(0.63-1.68)$ & & $0.72(0.38-1.37)$ & \\
\hline Lives with husband/companion & & 0.124 & & 0.393 & & 0.188 & & 0.708 \\
\hline No & 1 & & 1 & & 1 & & 1 & \\
\hline Yes & $1.25(0.94-1.66)$ & & $0.86(0.61-1.21)$ & & $0.78(0.54-1.13)$ & & $0.93(0.63-1.37)$ & \\
\hline Education (years of study) & & $<0.001$ & & 0.007 & & 0.010 & & 0.010 \\
\hline$\leq 9$ & 1 & & 1 & & 1 & & 1 & \\
\hline $10-12$ & $1.97(1.51-2.57)$ & & $1.20(0.77-1.88)$ & & $1.69(1.21-2.36)$ & & $1.67(1.15-2,43)$ & \\
\hline$\geq 13$ & $3.01(2.13-4.26)$ & & $1.56(0.91-2.67)$ & & $1.65(1.02-2.68)$ & & $1.79(1.05-3.07)$ & \\
\hline Household income per capita & & 0.932 & & 0.617 & & 0.887 & & 0.813 \\
\hline Quartile 1 (the poorest) & 1 & & 1 & & 1 & & 1 & \\
\hline Quartile 2 & $0.92(0.67-1.26)$ & & $0.65(0.43-0.98)$ & & $0.69(0.45-1.04)$ & & $0,76(0.48-1.20)$ & \\
\hline Quartile 3 & $0.94(0.69-1.28)$ & & $1.04(0.71-1.51)$ & & $0.99(0.67-1.46)$ & & $1.04(0.68-1.61)$ & \\
\hline Quartile 4 (the richest) & $0.96(0.70-1.33)$ & & $0.76(0.50-1.16)$ & & $0.86(0.56-1.32)$ & & $0.83(0.51-1.34)$ & \\
\hline Working & & 0.678 & & 0.292 & & 0.058 & & 0.101 \\
\hline Yes & 1 & & 1 & & 1 & & 1 & \\
\hline No & $0.95(0.75-1.20)$ & & $1.18(0.87-1.59)$ & & $1.35(0.99-1.85)$ & & $1.34(0.94-1.89)$ & \\
\hline \multicolumn{9}{|l|}{ Received guidance from a } \\
\hline health professional & & - & & 0.129 & & 0.195 & & 0.039 \\
\hline No & - & & 1 & & 1 & & 1 & \\
\hline Yes & - & & $1.35(0.92-1.97)$ & & $1.29(0.89-1.89)$ & & $1.60(1.01-2.52)$ & \\
\hline \multicolumn{9}{|l|}{ Lives in a neighborhood with } \\
\hline social cohesion & & 0.838 & & 0.952 & & 0.625 & & 0.794 \\
\hline Yes & 1 & & 1 & & 1 & & 1 & \\
\hline No & $1.02(0.76-1.36)$ & & $1.01(0.69-1.48)$ & & $0.91(0.61-1.35)$ & & $1.06(0.69-1.61)$ & \\
\hline
\end{tabular}

*Adjusted Odds Ratio; **95\%Confidence Interval. 
Adjusted model of factors associated with physical activity (PA) in the pre-gestational period and during pregnancy. Santa Catarina, Brazil, 2019.

\begin{tabular}{|c|c|c|c|c|c|c|c|c|}
\hline & $\begin{array}{l}\text { Pre-pregnancy } \\
\text { OR* }(I C 95 \%) * *\end{array}$ & $p$ & $\begin{array}{c}1^{\circ} \text { Trimester } \\
\text { OR* }(\mathrm{Cl} 95 \%)^{* *}\end{array}$ & $p$ & $\begin{array}{c}2^{\circ} \text { Trimester } \\
\text { OR* }(\mathrm{Cl} 95 \%) * *\end{array}$ & $p$ & $\begin{array}{c}3^{\circ} \text { Trimester } \\
\text { OR* }(\mathrm{C} 195 \%)^{* *}\end{array}$ & $p$ \\
\hline \multicolumn{9}{|l|}{ Lives in a neighborhood } \\
\hline with violence & & 0.441 & & 0.930 & & 0.470 & & 0.854 \\
\hline No & 1 & & 1 & & 1 & & 1 & \\
\hline Yes & $0.89(0.66-1.20)$ & & $0.98(0.67-1.44)$ & & $1.15(0.79-1.68)$ & & $1.04(0.68-1.60)$ & \\
\hline \multicolumn{9}{|l|}{ Lives in a neighborhood that } \\
\hline encourages physical activity & & 0.218 & & 0.108 & & 0.049 & & 0.418 \\
\hline No & 1 & & 1 & & 1 & & 1 & \\
\hline Yes & $1.16(0.92-1.46)$ & & $1.30(0.96-1.78)$ & & $1.39(1.01-1.91)$ & & $1.17(0.83-1.66)$ & \\
\hline
\end{tabular}

*Adjusted Odds Ratio; **95\%Confidence Interval.

possible to verify that in addition to the higher level of education, the interviewees who declared themselves to be brown were $32 \%$ more likely to be active compared to those who declared themselves to be white and women aged 35 to 46 years old, $51 \%$ higher in relation to adolescents.

Other results for age, self-reported color, living with a partner and in a neighborhood with social cohesion and episodes of violence, although had shown variations in specific measures among categories, did not show statistically significant associations with any of the outcomes in the crude and adjusted models.

\section{Discussion}

This study found a low prevalence of leisure-time physical activity among pregnant women, which decreased approximately $50 \%$ in the pregnancy period when compared to the pre-pregnancy period. Furthermore, having a higher level of education, receiving guidance from a health professional on the practice of PA and living in an environment that encourages the practice of PA are associated with the practice of physical activity among pregnant women. Previous research has also pointed out a low prevalence of physical activity among pregnant women, 15 including in Brazil, 2 placing the results found in this study in the four periods analyzed in line with the scientific literature in the area. Even the prevalence observed in the three months prior to pregnancy was lower than the estimated $31.5 \%$ for the general population of adult women in Brazil, 16 but higher than that observed in another study also conducted in the southern region, which found an approximate prevalence of women active in pre-pregnancy equal to $11 \% .2$

These values do not yet reflect the accumulation of knowledge about the importance of PA during pregnancy, since it is widely argued that in the absence of obstetric complications, pregnant women should be encouraged to remain active or initiate safe PA. This behavior can contribute to reducing the impact that chronic diseases can have on the health of both the pregnant woman and baby (such as the development of gestational diabetes and preeclampsia), as well as on the health system (such as emergency cesarean and development of mental disorders). ${ }^{17,18}$ For example, in comparison to studies in high-income countries, the low prevalence of LPA observed in this study is even more expressive, with prevalence rates exceeding $40 \%$ in some nations. 4 The findings in this study are still close to the values found recently in a low-income country, where it was found that only $8.4 \%$ of pregnant women were active during pregnancy. 19

The low prevalence of PA found is also opposed to the knowledge and technical assistance guidelines in this area, mainly in the pre-pregnancy period and in the second half of pregnancy. 20 This is because the benefits of regular PA generate more positive impacts on women of reproductive age, in relation to sedentary behavior, reducing the undesirable metabolic conditions that sedentary lifestyle can cause. 21 As for the second gestational trimester, it is known that it is considered the best period for the practice of PA, since the pregnant woman has already experienced the inconveniences of the beginning of pregnancy and is more willing, ensuring that she has already undergone prenatal care consultation and verified absence of gestational risk. 20

Education was associated with a higher prevalence of PA among pregnant women in the four periods analyzed, a finding in line with the main reports in the scientific literature on the subject.2,4 This factor may be linked to a greater degree of 
understanding and search for information about healthy life habits, as well as better jobs, housing and economic situations that would result in more time for this purpose. 22 Considering that many studies have found this association to be positive, it can be thought that the discrepancy in the percentage of active pregnant women between countries is related to the socioeconomic differences they present. The findings alert to the impact that a low rate of access to education can have on the population's health.

Another factor that had a positive association with the recommended LPA was receiving guidance from a health professional, an observation that is also in agreement with findings in the literature. 23,24 However, these same studies highlight that this association may be due to individual or intrinsic characteristics of pregnant women that provide greater concerns for professionals with this theme, such as Gestational Diabetes Mellitus (GDM) and pregnant women's interest. 23,24 Thus, there are reports that the lack of counseling and information may constitute a barrier to PA, 25 concomitant with reports that younger, single, low-educated, and lower income women are less likely to receive information about prenatal physical activity. 23

Living in a neighborhood that offers structure for PA was positively associated with the outcome in the second trimester of pregnancy, in line with other studies that found that structural facilities for the practice of physical activity help promote physical activity for women, especially during leisure time, since they have an impact on their behavior regardless of the knowledge or guidance they receive. $25 \mathrm{~A}$ research conducted in USA in 2019 showed that the distance between the residence and the nearest park is inversely related to the chance of the pregnant woman reaching appropriate levels of PA, noting that aspects of the neighborhood such as ease of movement, access to public transport, distance from recreation facilities and road networks are associated with physical activity during pregnancy and postpartum. ${ }^{10}$ Still, another study demonstrated that walking is part of the main modalities of PA practiced among pregnant women, showing the importance of neighborhoods with a structure favorable to these practices. 26

In summary, this study collaborates with scientific discussions regarding the incentive of LPA in prenatal care, inserting in the literature new data on the prevalence of pregnant women physically active during leisure and the effects of sociodemographic factors and the context of the living environment on this outcome. It is believed that these may be impor- tant evidence for the management of the health care network for pregnant women and for directing actions with a focus on the promotion of LPA during pregnancy.

In accordance with the main results of this study, this management must consider the effect of individual and contextual inequalities on the behavior of pregnant women, directing their strategies to groups with a lower educational level and worse conditions in the neighborhood environment for outdoor practices. Then, given the positive association with the guidance of a health professional, this can be a very important moment for the perfusion of these actions, considering the unique opportunity to monitor these vulnerabilities.

This meeting between health professionals and pregnant women usually takes place mainly in primary care, which is the strategic place for the development of actions by health professionals that aim to assist with the promotion of body practices and physical activity. 27 Actions that employ diversified pedagogical strategies to qualify health education actions and that reach people with less education, in addition to the search for solutions in less favorable territories to PA, may be on the agenda of primary care professionals.

Even though there is no significant association with the outcomes in this study, there is theoretical support 2,4 to consider income, work, living with a partner and self-declared white color in all studies on this topic, as these conditions can interfere with the attitude towards PA among women in the reproductive period, especially during pregnancy. A Japanese study 28 investigated the impact that these factors can have on the physical and mental health of pregnant women, noting this association and emphasizing that the possibility of improving this social capital increases the chance that the pregnant woman will have a healthier pregnancy. Another scientific report drew attention to the fact that exhaustive occupational activities during pregnancy may be related to the lower involvement of pregnant women with LPA, as they may be more indisposed and even oriented to reduce other situations that require some physical effort, 29 which could explain this null association in this study.

One of the limitations of this study is that the information was self-reported and refers to the months prior to the interview, which can result in memory bias and generate impact on prevalence measures of physical activity. In addition, interviewees may choose to report information that they consider to be more socially accepted. However, these limitations are reported and considered accept- 
able in studies with the same theme and forms of measurement, since the moment of information collection was close to the investigated events. ${ }^{2}$ In addition, this study analyzed only subjective data about the neighborhood environment. Some authors suggest that using objective data on the built and social environment, concomitant with perceived data on the environment, better represents the living environment. 9

This study found that the prevalence of sufficient leisure-time physical activity is low among the investigated pregnant women. It also showed that specific neighborhood's characteristics encourages

\section{References}

1. Kehler AK, Heinrich KM. A selective review of prenatal exercise guidelines since the 1950s until present: Written for women, health care professionals, and female athletes. Women Birth. 2015; 8 (4): e93-e98

2. Coll C, Domingues M, Santos I, Matijasevich A, Horta BL Hallal PC. Changes in Leisure-Time Physical Activity From the Prepregnancy to the Postpartum Period: 2004 Pelotas (Brazil) Birth Cohort Study. J Phys Act Health. 2016; 13 (4): 361-5.

3. van Mulken MR, McAllister M, Lowe JB. The stigmatisation of pregnancy: societal influences on pregnant women's physical activity Behaviour. Cult Health Sex. 2016; 18 (8): 921-35.

4. Lindqvist M, Lindkvist M, Eurenius E, Persson M, Ivarsson A, Mogren I. Leisure time physical activity among pregnant women and its associations with maternal characteristics and pregnancy outcomes. Sex Reprod Health. 2016; 9: 14-20.

5. Tavares JS. et al. Padrão de atividade física entre gestantes atendidas pela estratégia saúde da família de Campina Grande - PB. Rev Bras Epidemiol. 2009; 12 (1): 10-9.

6. Sallis JF, Cervero RB, Ascher W, Henderson KA, Kraft MK, Kerr J. An ecological approach to creating active living communities. Annu Rev Public Health. 2006; 27: 297-322.

7. Laraia B, Messer L, Evenson K, Kaufman JS Neighborhood factors associated with physical activity and adequacy of weight gain during pregnancy. J Urban Health. 2007; 84 (6): 793-806.

8. WHO (World Health Organization). Physical activity for health More active people for a healthier world: draft global action plan on physical activity 2018-2030. Geneva; 2018.

9. McEachan RR, Prady SL, Smith G, et al. The association between green space and depressive symptoms in pregnan women: moderating roles of socioeconomic status and physical activity. J Epidemiol Community Health. 2016; 70 (3): 253-59.

10. Porter AK, Rodríguez DA, Frizzelle BG, Evenson KR. The Association between Neighborhood Environments and Physical Activity from Pregnancy to Postpartum: a Prospective Cohort Study. J Urban Health. 2019; 96 (5): 703-19. the practice of outdoor activities, and having greater education and receiving guidance from a health professional for the practice of physical activity increase the chance of women in reproductive age and pregnant women to perform leisure time physical activity.

\section{Author's contribution}

This study is the result of the master's thesis by Silva VRS, under the supervision of Boing AF. All authors approved the final version of the article.

11. Santa Catarina. Sistema de Informação sobre Nascidos Vivos. [acesso em 27 out 2019]. Disponível emhttp://www.saude.sc.gov.br/cgi/deftohtm.exe?sinasc.def.

12. IBGE (Instituto Brasileiro de Geografia e Estatística). Estimativas da população. [acesso 28 set 2019]. Disponível em: https://sidra.ibge.gov.br/tabela/6579\#resultado.

13. Santa Catarina. Secretaria de Estado da Saúde. Rede Interagencial de Informações para a Saúde (RIPSA). [acesso 30 out 2019]. Disponível em: http://200.19.222.8/cgi/tabcgi.exe?Ind_Recursos/leitos_E2 3 graf.def.

14. Birsner ML, Gyamfi-Bannerman C. Physical Activity and Exercise During Pregnancy and the Postpartum Period: ACOG Committee Opinion, Number 804. Obstet Gynecol. 2020; 135 (4): 178-88.

15. Condello G, Puggina A, Aleksovska K, et al. Behavioral determinants of physical activity across the life course: a "DEterminants of DIet and Physical ACtivity" (DEDIPAC) umbrella systematic literature review. Int J Behav Nutr Phys Act. 2017; 14 (1): 58.

16. Brasil. Ministério da Saúde. Vigitel 2017: vigilância de fatores de risco e proteção para doenças crônicas por inquérito telefônico. Brasília: Ministério da Saúde, 2018.

17. Tsakiridis I, Bakaloudi DR, Oikonomidou AC, Dagklis T, Chourdakis M. Exerciseduringpregnancy: a comparative review ofguidelines. J Perinat Med. 2020; 48 (6): 519-25.

18. Nielsen EN, Andersen PK, Hegaard HK, Juhl M. Mode of Delivery according to Leisure Time Physical Activity before and during Pregnancy: A Multicenter Cohort Study of Low-Risk Women. J Pregnancy. 2017; 2017: 6209605.

19. Hailemariam TT, Gebregiorgis YS, Gebremeskel BF, Haile TG, Spitznagle TM. Physical activity and associated factors among pregnant women in Ethiopia: facility-based crosssectional study. BMC Pregnancy Childbirth. 2020; 20 (1) 92.

20. Nascimento SLet al. Recomendações para a prática de exercício físico na gravidez: uma revisão crítica da literatura. Rev Bras Ginecol Obstet. 2014; 36 (9): 423-31.

21. Flannery C, Dahly D, Byrne M, et al. Social, biological, behavioural and psychological factors related to physical activity during early pregnancy in the Screening for 
Pregnancy Endpoints (Cork, Ireland) cohort study. BMJ Open. 2019; 9 (6): e025003.

22. Cannella D, Lobel M, Monheit A. Knowing is believing: information and attitudes towards physical activity during pregnancy. J Psychosom Obstet Gynaecol. 2010; 31 (4): 236-42.

23. Doran FM, Buckley NA. Walking patterns in pregnancy. Aust J Prim Health. 2013; 19 (3): 213-8

24. Coll CV, Domingues MR, Gonçalves H, Bertoldi AD Perceived barriers to leisure-time physical activity during pregnancy: A literature review of quantitative and qualitative evidence. J Sci Med Sport. 2017; 20 (1): 17-25.

25. Toghiyani Z, Kazemi A, Nekuei N. Physical activity for healthy pregnancy among Iranian women: Perception of facilities versus perceived barriers. J Educ Health Promot. 2019; 8: 3

26. Menichini D, Fanetti O, Molinazzi MT, Facchinetti F, Ricchi A, Neri I. Physical activity in low risk pregnant women: a cross-sectional study. Clin Ter. 2020; 171 (4): 328-34.

Received on January 18, 2021

Final version presented on May 18, 2021

Approved on July 19, 2021
27. Brasil. Ministério da Saúde. Portaria $n^{\circ}$ 2.436. Política Nacional de Atenção Básica. [acesso 26 out 2019]. Disponível

https://bvsms.saude.gov.br/bvs/saudelegis/gm/2017/prt243 62209 2017.html.

28. Morozumi R, Matsumura K, Hamazaki K, et al. Impact of individual and neighborhood social capital on the physical and mental health of pregnant women: the Japan Environment and Children's Study (JECS). BMC Pregnancy Childbirth. 2020; 20 (1): 450.

29. Cai C, Vandermeer B, Khurana R, et al. The impact of occupational activities during pregnancy on pregnancy outcomes: a systematic review and metaanalysis. Am J Obstet Gynecol. 2020; 222 (3): 224-38. 